See Article page 338.

\section{Commentary: Hand-sewn or stapled esophageal anastomosis: Ask not what your anastomosis can do for you, but what you can do for your esophageal anastomosis}

\author{
Richard S. Lazzaro, MD, FACS, a,b and
} Matthew L. Inra, MD ${ }^{\mathrm{a}, \mathrm{b}}$

Esophagogastric anastomosis is a critical component of esophagectomy; anastomotic failures contribute to shortterm and long-term morbidity as well as mortality. ${ }^{1}$ To improve outcomes, there are many opportunities to optimize anastomotic healing through pre-resectional approaches to intraoperative technique combined with anastomotic adjuncts. A preoperative approach to conduit augmentation can involve ischemic preconditioning of the gastric conduit via preoperative transarterial embolization of left gastric, right gastric and splenic arteries (2) to make the gastric blood supply dependent on the right gastroepiploic artery. This approach avoids a sudden decrease in gastric blood flow when conventional single-stage surgery is performed; ischemic preconditioning has been shown to result in "significantly reduced ... loss of (tissue blood flow)" in the gastric tube during preparation... (and was) effective in maintaining adequate (tissue blood flow) $)^{2}$ to reduce the incidence of anastomotic leak. Ischemic preconditioning of the conduit can also be performed via a surgical approach. ${ }^{3}$ Additional preoperative considerations include choice of surgical approach, which

\footnotetext{
From the ${ }^{\mathrm{a} D e p a r t m e n t}$ of Cardiovascular and Thoracic Surgery, Northwell Health Lenox Hill Hospital, New York; and ${ }^{\mathrm{b}}$ Donald and Barbara Zucker School of Medicine at Hofstra Northwell, Hempstead, NY.

Disclosures: The authors reported no conflicts of interest.

The Journal policy requires editors and reviewers to disclose conflicts of interest and to decline handling or reviewing manuscripts for which they may have a conflict of interest. The editors and reviewers of this article have no conflicts of interest.

Received for publication Aug 8, 2021; revisions received Aug 8, 2021; accepted for publication Aug 11, 2021; available ahead of print Sept 7, 2021.

Address for reprints: Richard S. Lazzaro, MD, FACS, Department of Cardiovascular and Thoracic Surgery, Northwell Health, Lenox Hill Hospital, 130 East 77th St, 4 Black Hall, New York, NY 10075 (E-mail: Rlazzaro@northwell.edu). JTCVS Open 2021;7:355-6

2666-2736

Copyright (c) 2021 The Author(s). Published by Elsevier Inc. on behalf of The American Association for Thoracic Surgery. This is an open access article under the CC BY-NC-ND license (http://creativecommons.org/licenses/by-nc-nd/4.0/).

https://doi.org/10.1016/j.xjon.2021.08.015
}

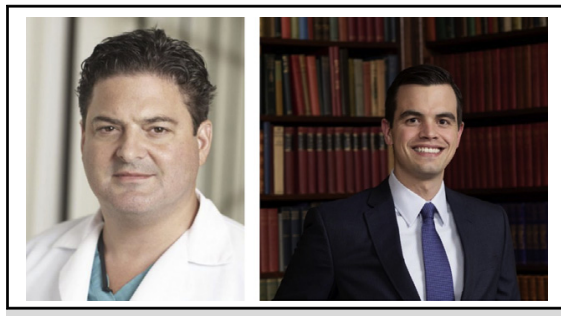

Richard S. Lazzaro, MD, FACS, and Matthew L. Inra, MD

\section{CENTRAL MESSAGE \\ Esophageal anastomotic tech- nique is more than just hand- sewn versus staples; a vascularized conduit and a well- constructed anastomosis without tension carry the day.}

also affects anastomotic complications as "anastomotic leaks and RLN injury appear to be decreased with a transthoracic approach."4,5

Conduit creation and handling is of paramount importance, as the right gastroepiploic artery provides the conduit with blood and the proximal aspect of the conduit relies upon a "microscopic network of capillaries and arterioles,"6,7 whereas narrow conduits "minimize the dependency of the lesser curvature of the stomach on these collateral vessels." ${ }^{7}$ Intraoperative assessment of gastric tube perfusion with indocyanine green coupled with nearinfrared imaging can be used to assess conduit perfusion as well as the choice of anastomotic location. ${ }^{1}$ Intraoperative adjuncts, including nasogastric tube decompression and pyloric drainage procedures to limit gastric conduit distension, may reduce the incidence of anastomotic leak, whereas buttressing the anastomosis with omental or thymic flaps may protect the patient from complications related to anastomotic leak. ${ }^{8,9}$

In this month's issue of the Journal, Järvinen and colleagues ${ }^{10}$ performed a meta-analysis of 19 studies, which included 2123 patients, to assess the impact of anastomotic technique, hand-sewn or stapled, upon anastomotic leak, stricture, and 30-day mortality after esophagectomy. The definition of anastomotic leak was not standardized between the analyzed studies. Although the authors identified a "signal" favoring lower anastomotic leak and stricture with stapled anastomosis over hand-sewn, 30-day mortality was not impacted. The authors identified multiple 
limitations, including studies that were performed over a 25-year time span (with potential bias from differences in induction therapy and postoperative treatment protocols) as well as a paucity of data from minimally invasive esophagectomy approaches, leading the authors to conclude that the "most important factor in anastomotic technique is a well vascularized anastomosis constructed without tension rather than a specific anastomotic technique." 10

The statistical analyses performed in the current study are descriptive, and it is not possible to conclude that one anastomotic technique is superior to another as pertains to leak, stricture, and mortality. The data analytics of the current study are descriptive and not diagnostic of causality nor predictive of an outcome sufficient to guide the surgeon's decision-making prospectively when it comes to the choice between hand-sewn versus stapled anastomosis. At the end of the day, ischemic preconditioning resonates with us but requires a separate intervention and is not being performed by most surgeons.

Consequently, minimizing conduit handling to limit microvascular arcade disruption, use of perfusion imaging to aid in assessment of conduit viability, as well as anastomotic location with a tension-free anastomosis buttressed by local tissues are actionable items we can currently perform while the debate of hand-sewn versus stapled anastomosis continues or ends. Ask not what your anastomosis can do for you, but what you can do for your esophageal anastomosis.

\section{References}

1. Bonavina L. Progress in the esophagogastric anastomosis and the challenges of minimally invasive thoracoscopic surgery. Ann Transl Med. 2021;9:907.

2. Isomura T, Itoh S, Endo T, Akiyama S, Maruyama K, Ishiguchi T, et al. Efficacy of gastric blood supply redistribution by transarterial embolization: preoperative procedure to prevent postoperative anastomotic leaks following esophagoplasty for esophageal carcinoma. Cardiovasc Intervent Radiol. 1999;22:119-23.

3. Mingol-Navarro F, Ballester-Pla N, Jimenez-Rosellon R. Ischaemic conditioning of the stomach previous to esophageal surgery. J Thorac Dis. 2019;11(suppl 5): S663-74.

4. Pennathur A, Zhang J, Chen H, Luketich JD. The "best operation" for esophageal cancer? Ann Thorac Surg. 2010;89:S2163-7.

5. Biere SS, Maas KW, Cuesta MA, van der Peet DL. Cervical or thoracic anastomosis after esophagectomy for cancer: a systematic review and meta-analysis. Dig Surg. 2011;28:29-35.

6. Liebermann-Meffert DM, Meier R, Siewert JR. Vascular anatomy of the gastric tube used for esophageal reconstruction. Ann Thorac Surg. 1992;54:1110-5.

7. Mentzer S. Esophageal anstomosis. Op Tech Thorac Cardiovasc Surg. 2000;5: 231-41.

8. Watkins AA, Kent MS, Wilson JL. Surgical adjuncts during esophagectomy. Thorac Surg Clin. 2020;30:315-20.

9. Bonavina L, Asti E, Sironi A, Bernardi D, Aiolfi A. Hybrid and total minimally invasive esophagectomy: how I do it. J Thorac Dis. 2017;9(suppl 8): S761-72.

10. Järvinen T, Cools-Lartigue J, Robinson E, Räsänen J, Ilonen I. Hand-sewn versus stapled anastomoses for esophagectomy: we will probably never know which is better. J Thorac Cardiovasc Surg Open. 2021;7:338-52. 